\title{
Tecnologia social de saneamento básico: reflexões a partir de uma ação extensionistano assentamento Nova São Carlos
}

\author{
Mario Berni de Marque ${ }^{1}$ \\ Marcel Fantin ${ }^{2}$ \\ João Fontes Lopes Neto ${ }^{3}$ \\ Julia Maria Dos Santos Silva ${ }^{4}$ \\ Kevin Yukihiro Goia ${ }^{5}$
}

RESUMo: O saneamento básico é essencial para a promoção da saúde pública e do desenvolvimento sustentável. O não atendimento desse direito em assentamentos rurais acarreta uma dinâmica pontilhada de negatividades e demanda ferramentas, técnicas e tecnologias adequadas e adaptadas a uma diversidade de ambientes e contextos. Nesse sentido, esse artigo apresenta uma experiência de prática extensionista voltada para a implementação de uma tecnologia social de saneamento no assentamento Nova São Carlos (São Carlos - SP). A atividade desenvolvida pelo grupo GEISA (Grupo de Estudos e Intervenções Socioambientais), da Universidade de São Paulo, selecionou um lote através de um diagnóstico socioambiental e, com base na demanda e no diálogo com os assentados, foi proposta e implementada uma tecnologia social de saneamento descentralizado. Com isso, buscou-se valorizar a saúde dos moradores e promover a educação ambiental para as pessoas envolvidas na atividade. Ao final, são apresentadas reflexões sobre a potencialidade do uso de tecnologias sociais de saneamento no campo das políticas públicas, considerando também o papel da universidade no fomento deste debate a partir de práticas extensionistas.

Palavras-chave: Saneamento Rural. Tecnologia Soial. Assentamento. Geisa. Filtro Anaeróbio.

\section{SOCIAL TECHNOLOGY FOR BASIC SANITATION: REFLECTIONS FROM AN EXTENSIONIST ACTION IN THE Nova São Carlos Settlement}

AbstraCt: Basic sanitation is essential for promoting public health and sustainable development. Failure to comply with this right in rural settlements leads to a negative dynamic and demands tools, techniques and technologies that are appropriate and adapted to a variety of environments and contexts. In this sense, this article presents an experience of extensionist practice aimed at the implementation of a social sanitation technology in the Nova São Carlos settlement (São Carlos - SP). The activity developed by the GEISA group (Socio-environmental Studies and Interventions Group), of the University of São Paulo, selected a rural property through a socio-environmental diagnosis and, based on demand and dialogue with the settlers, a social technology of decentralized sanitation was proposed and implemented. With this, we sought to value the health of residents and promote environmental education for people involved in the activity. At the end, reflections on the potential use of social sanitation technologies in the field of public policies are presented,

\footnotetext{
${ }^{1}$ Graduando em Engenharia Ambiental pela Universidade de São Pualo. E-mail:mariodmarque@gmail.com

${ }^{2}$ Docente no Intituto de Arquitetura e Urbanismo pela Universidade de São Paulo. E-mail: marcel.fantin@hotmail.com

${ }^{3}$ Graduando em Engenharia Ambiental pela Universidade de São Pualo. E-mail: joao.fontes.neto@usp.br

${ }^{4}$ Graduando em Engenharia Ambiental pela Universidade de São Pualo. E-mail: julia.santos.silva@usp.br

${ }^{5}$ Graduando em Engenharia Ambiental pela Universidade de São Pualo. E-mail: kevinyukihiro@gmail.com
} 
also considering the role of the university in fostering this debate based on extensionist practices.

KEYwORDS: Rural sanitation. Social technology. Settlement. GEISA. Anaerobic filter.

\section{INTRODUÇÃo}

O saneamento básico é um direito assegurado pela Constituição Federal (BRASIL, 1988) e envolve um conjunto de medidas que objetivam garantir a saúde e o bem-estar da população, assim como melhorar e preservar as condições ambientais. A Lei Federal no. 11.445/2007, que estabelece as diretrizes nacionais para o saneamento básico, define esse campo de ação do Estado como o conjunto dos serviços, infraestruturas e instalações operacionais de abastecimento de água, esgotamento sanitário, limpeza urbana, drenagem urbana, manejos de resíduos sólidos e de águas pluviais (art. $3^{\circ}$, inc. I).

Em que pese o Brasil tenha apresentado avanços importantes nos diversos campos de atuação voltados ao saneamento básico, a ausência de investimentos nesse setor nas últimas décadas tem deixado o país ainda longe das metas de universalização desses serviços. ${ }^{1}$

Os resultados da Pesquisa Nacional por Amostragem de Domicílios (PNAD IBGE) realizada em 2015 demonstram que 14,6\% da população brasileira ainda não possui acesso à rede de distribuição de água e 40,9\% não é atendida pela coleta de esgoto sanitário. Além disso, Souza et. al (2014) argumentam que mesmo na parcela da população ligada aos sistemas de abastecimento de água e coleta de esgoto, a qualidade desses tratamentos varia e muitas vezes são insuficientes, mostrando também a fragilidade nos dados da PNAD que não abordam o acesso qualitativo ao saneamento.

Na zona rural, os índices de acesso são, historicamente, ainda menores em face da ineficiência, escassez e até inexistência de saneamento (SIMONATO et al., 2019). Os autores apontam fatores como: isolamento das comunidades; falta de investimento público no setor, incluindo tecnologias de baixo custo, e falta de vontade política para atender essas comunidades. A visão de Simonato et al. (2019) corrobora com o entendimento da falta de políticas públicas nos locais onde reside a população vulnerável e fragilizada como essência desse problema (MURTHA;CASTRO; HELLER, 2015; HOLGADO-SILVA et al., 2014). Segundo o Plano Nacional de Saneamento Básico (PLANSAB) de 2019, 60,3\% das residências rurais não possuem soluções adequadas para o afastamento do esgoto sanitário, sendo este conduzido,

\footnotetext{
${ }^{1}$ Em 2013 foram investidos no Brasil R \$ 13,2 para apenas R \$ 10,96 em 2017, de acordo com o Sistema Nacional de Informações sobre Saneamento (SNIS) (TRATA BRASIL, 2020).
} 
principalmente, para fossas rudimentares $(48,6 \%)$ ou para valas, rios e lagos $(11,7 \%)$.

As fossas rudimentares (também conhecidas como negras ou caipiras) envolvem a disposição do esgoto bruto em um buraco sem impermeabilização do solo. Isso facilita tanto a contaminação ${ }^{2}$ de lençóis freáticos pelos poluentes presentes no esgoto (como sólidos em suspensão, matéria orgânica, nutrientes e patógenos) como a propagação e vetorização de doenças de vínculo hídrico como diarreias, infecções por nematóides, bactérias, vírus e protozoários (GERMANI; VILLWOC; CHIES, 2020; BUGELLI; FELÍCIO, 2019; FORESTI, 2013; GONÇALVES, 2003; VON SPERLING, 1996).

Gondim (2008) evidencia a relação entre a falta de saneamento básico e saúde pública, cuja escassez de medidas sanitárias estão relacionados com patologias infectocontagiosas. Estimativas apontam que $88 \%$ da carga dessas epidemiologias estão relacionadas com a falta de tratamento de água, esgotamento sanitário e hábitos de higiene inadequados, afetando principalmente crianças que se encontram em localidades de baixa condições de salubridade ambiental ${ }^{3}$ (SILVA et al., 2017; PRUSS et al., 2002).

Para Batista e Silva (2006), a insalubridade ambiental está relacionada com a falta de infraestruturas sanitárias capazes de prevenir e conter a ocorrência de doenças e Heller (1998) pondera que levar infraestruturas para toda população permite promover a saúde pública pelo saneamento. $\mathrm{O}$ mesmo autor avalia que, para se atingir esse objetivo, é preciso também avançar nas pesquisas científicas, experiências alternativas e demais estudos voltados à universalização do saneamento básico.

Para além das questões ambientais e de saúde pública, o acesso ao saneamento também se enquadra como empoderamento da cidadania. Nesse sentido, Leoneti, Prado e Oliveira, (2011) apud Pitassi (2019), ponderam que a questão do saneamento básico está relacionada de forma íntima com as ideias de mínimo existencial, dignidade humana e acesso à cidadania sanitária.

A exclusão de acesso à infraestrutura de saneamento amplia a desigualdade social e contribui para o agravamento de diversos problemas sociais, econômicos, culturais, educacionais, psicológicos, ambientais e de saúde, sendo estas variáveis amplificadas quando a questão é atrelada ao meio rural (MOISÉS et al., 2010; SAWAIA, 2009).

Nesse contexto, a abordagem de promoção de saneamento na zona rural deve ser própria e distinta da convencional usada para os sistemas urbanos centralizados, inviáveis para locais que apresentam baixa densidade habitacional e grandes distâncias entre residências. Nesses casos são recomendados os sistemas descentralizados (in

\footnotetext{
${ }^{2}$ Utiliza-se a definição de Jordão e Pessôa (1975): "Quando ocorre a presença de substâncias tóxicas ou de organismos patogênicos oferecendo risco à saúde da população”.

${ }^{3}$ Para ARAVÉCHIA JÚNIOR (2010), conceitua-se o termo como: "conciliação entre a qualidade de vida, a qualidade ambiental e as condições ideais para desenvolver um ambiente saudável e socialmente igual”.
} 
situ) para reduzir a proporção de pessoas sem acesso ao esgotamento sanitário (DE MARQUE; FANTIN, 2018; LOTFI, 2016; LIBRALATO; GHIRARDINI; AVEZZU, 2012). Abordando tecnologias acessíveis e com viabilidade econômica e ambiental.

Tonetti et al. (2018) abordam diversos sistemas descentralizados para tratamento de esgoto sanitário em comunidades isoladas e/ou rurais, destacando as fossas sépticas biodigestoras, tanque séptico, filtro anaeróbio, círculo de bananeiras, banheiro seco compostável, dentre outras.

Entretanto, para além da viabilidade econômica, ressalta-se a necessidade da viabilidade social e cultural para as tecnologias serem bem aceitas e exercerem sua função (DAGNINO, 2014).

Assim, para a ampliação do acesso ao tratamento de esgoto em zonas rurais, a adoção de tecnologias sociais é uma alternativa que permite respeitar o modo de vida local considerando as condições sociais, ambientais, econômicas e culturais ${ }^{4}$.

Para Rodrigues e Barbieri (2008, p.1076), para ser considerada social, uma tecnologia deve corroborar com os seguintes critérios:

1. Razão de ser da tecnologia social - atender as demandas sociais concretas vividas e identificadas pela população;

2. Processo de tomada de decisão - processo democrático e desenvolvido a partir de estratégias especialmente dirigidas à mobilização e à participação da população;

3. Papel da população - há participação, apropriação e aprendizado por parte da população e de outros atores envolvidos;

4. Sistemática - há planejamento, aplicação ou sistematização de conhecimento de forma organizada;

5. Construção do conhecimento - há produção de novos conhecimentos a partir da prática;

6. Sustentabilidade - a tecnologia social visa à sustentabilidade econômica, social e ambiental;

7. Ampliação de escala - gera aprendizagem que serve de referência para novas experiências.

Abrangendo os conceitos anteriormente abordados, o grupo de extensão universitária GEISA (Grupo de Estudos e Intervenções Socioambientais) da Escola de Engenharia de São Carlos da Universidade de São Paulo (EESC/USP) buscou realizar uma prática extensionista para a edificação de uma tecnologia social de saneamento básico em diálogo com a comunidade rural do assentamento Nova São Carlos (TAVER; VARISON; MONTAÑO, 2017).

\footnotetext{
${ }^{4}$ Entende-se Tecnologia Social por "um conjunto de técnicas, metodologias transformadoras, desenvolvidas e/ou aplicadas na interação com a população e apropriadas por ela, que representam soluções para inclusão social e melhorias das condições de vida” (ITS, 2004: 26). Já Dagnino (2002: 209-210) define Tecnologia Social como “aquela que busca adequar a tecnologia convencional (e, inclusive, conceber alternativas) adotando critérios suplementares aos técnico-econômicos usuais e aplicandoos a processos de produção e circulação de mercadorias visando a otimizar suas implicações".
} 
O objetivo deste trabalho foi aproximar o meio acadêmico da zona rural, em especial do assentamento rural Nova São Carlos, através de um processo educativo, crítico e transformador de extensão universitária.

Atrelado a este propósito, busca-se fomentar o debate entre os agentes envolvidos (alunos e alunas, comunidade assentada e terceiros interessados) quanto a importância do saneamento rural por meio de uma experiência prática de aplicação de uma tecnologia social.

Além disso, toda a prática desenvolvida partiu do entendimento e da compreensão de que a luta pela Reforma Agrária deve aliar o direito à terra ao direito à qualidade de vida que traz, entre seus componentes, o saneamento básico.

Para tanto, essa prática extensionista envolveu diálogos e contatos pessoais com os assentados, visitas de campo ao assentamento e a elaboração de um diagnóstico quantitativo para melhor compreender a realidade local.

Foram entrevistados 38 residentes dos 83 lotes existentes no assentamento, dos quais metade haviam fossas rudimentares para os esgotos domésticos, destinação esta considerada não adequada para promoção da segurança sanitária, o que reforça a importância do trabalho descrito neste artigo.

Com relação à saúde, o mesmo trabalho indica a ocorrência de dengue, principalmente em crianças de até 12 anos de idade, cuja doença possui veiculação hídrica. Ademais, gripes e resfriados foram constatados em diversas faixas etárias. ${ }^{5}$

\section{O Assentamento Nova São Carlos}

Em âmbitos nacional, regional ou local, os assentamentos são uma das formas mais objetivas de promover a reforma agrária, concretizando a luta pela terra por parte da população que exige a efetivação de seus direitos constitucionais à moradia, qualidade de vida, desenvolvimento e trabalho (FERRANTE; WHITAKER, 2013; SOUZA-ESQUERDO; BERGAMASCO, 2011).

O Assentamento de Reforma Agrária Nova São Carlos (Figura 1) se localiza na região sul do município de São Carlos, interior de São Paulo (coordenadas 225'20"S e 4752'14"W), às margens da rodovia Domingos Innocentini (SPA - 149/215), na bacia hidrográfica do Ribeirão Feijão.

De acordo com as lideranças e moradores do assentamento (TABARIN; FANTIN,2018), a mobilização da ocupação começou entre 2006 e 2007 na área onde havia uma monocultura de eucalipto em área pertencente à FEPASA (Ferrovia Paulista S.A.) e arrendada pela CONPACEL (Consórcio Paulista de Papel e Celulose, antiga RIPASA) através de um contrato com governo federal.

\footnotetext{
${ }^{5}$ Diagnósticos e caracterizações, mesmo que básicos, servem como referência para determinar as vocações, suscetibilidades e obter informações importantes dos fatores ambientais, geográficos, históricos, econômicos e sociológicos do local (SOUZA, 2000; AB'SABER, 1969).
} 
Figura 1 - Localização do Assentamento Nova São Carlos em São Carlos/SP.

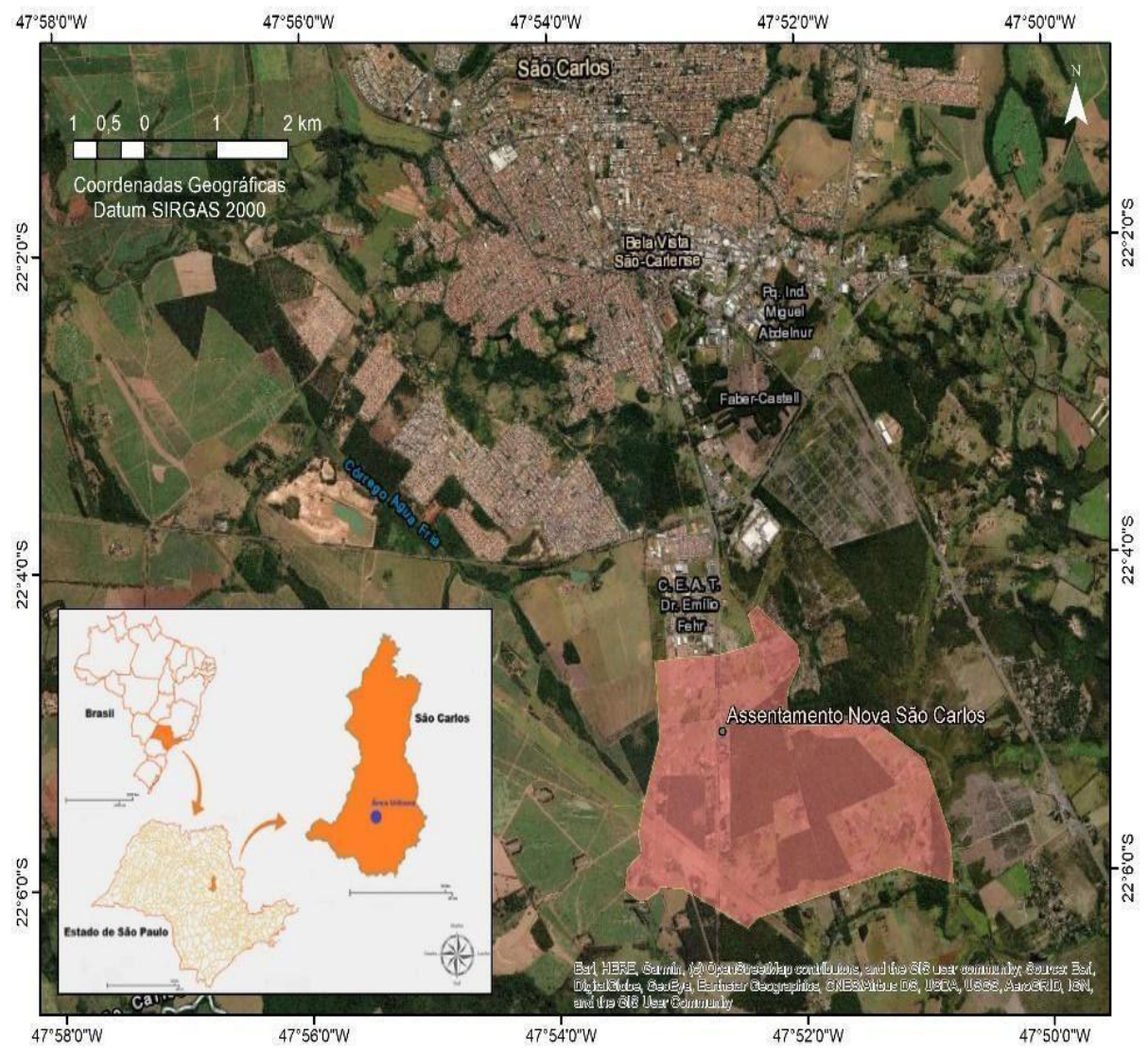

Fonte: Autoria Própria.

Devido às dificuldades para o cultivo da terra e de organização social, a ocupação se deu, de fato, em setembro de 2008, contando com 150 a 200 famílias e, após muita luta social, o assentamento foi reconhecido apenas em agosto de 2009, conforme o Relatório de Gestão do Instituto Nacional de Colonização e Reforma Agrária (INCRA, 2009), registrando 110 famílias, em uma área total de 1.158,50 hectares. Atualmente, residem cerca de 83 famílias no assentamento, muitas com dificuldades de acesso a água, esgotamento, educação, saúde, lazer, dentre outros fatores essenciais à qualidade de vida (PERRIN; FERREIRA, 2017).

\section{Metodologia}

\section{SELEÇÃo DO LOTE}

Para implementação da tecnologia social, levou-se em consideração a neces- 
sidade de garantir o saneamento tendo em vista os aspectos sociais, ambientais e econômicos do lote a partir do diagnóstico quantitativo realizado pelo GEISA (TAVER; VARISON; MONTAÑO, 2017).

Utilizando aspectos determinados por Souza (2000) para compreender as vocações, suscetibilidades e obter informações importantes a partir do diagnóstico, foi elaborada uma simplificação da matriz FOFA (Fortalezas, Oportunidades, Fraquezas e Ameaças) para orientar a escolha do lote. Desta forma, a matriz FOFA simplificada foi dividida em (1) potencialidades, (2) fragilidades e (3) fatores relevantes.

Os aspectos dos lotes foram divididos em: potencialidades, fragilidades e fatores relevantes. Assim, nas potencialidades foram evidenciados os conhecimentos em construção civil, técnicas de cultivo e posse de ferramentas. Nas fragilidades, retrata-se situações precárias de saúde, saneamento, sociais e econômicas e, quanto aos fatores relevantes, foram elencados o número de integrantes na família, renda per capita, tipo de casa (barraco, alvenaria inacabada, etc), acesso às políticas de instalação, interesse em participar do projeto, dentre outros.

Após análise do diagnóstico quantitativo, selecionou-se o lote 65, evidenciado pela necessidade ambiental de promover a destinação correta das Águas Negras, visto que a fossa rudimentar em sua residência estava exposta, propiciando a contaminação e vetorização de doenças, mau cheiro e acidentes com animais domésticos, o que demonstra, também, questões de segurança para a promoção do saneamento neste lote.

Em seguida, o grupo entrou em contato com a moradora do lote para informar a vontade dos discentes em realizar a atividade extensionista. Após diálogo com a moradora, a mesma aceitou trabalhar em conjunto com o grupo e demonstrou de forma pormenorizada os problemas cotidianos associados à falta de saneamento em sua residência.

Foi constatado que os moradores dividiam o encanamento do esgoto entre águas de origem do vaso sanitário e águas cinzas (água proveniente de pias, chuveiros, tanques) a qual faziam o reuso para lavagem de pisos.

Em uma segunda visita ao lote, foi construído um diálogo para avaliar a melhor forma de enfrentamento do problema retratado, ou seja, as possibilidades de realizar o tratamento das águas do vaso sanitário, visto que as águas cinzas eram reutilizadas no cotidiano. Deste modo, foram levantadas hipóteses de tecnologias como tanque de evapotranspiração, banheiro seco, fossas sépticas sequenciais, dentre outras. 
Tendo em vista o conceito de Tecnologia Social, buscou-se na literatura alternativas para promover o tratamento do esgoto descentralizado e que poderiam ser aplicadas naquele contexto.

Importante observar que a pesquisa e a identificação da tecnologia mais adequada às demandas do lote selecionado acabaram por manifestar na família grande interesse em participar do projeto, o que é fundamental para aceitação e apropriação da tecnologia.

\section{DEFINIÇÃo DA TECNOLOGIA}

As águas residuárias domésticas podem ser divididas conforme seu uso, sendo denominada Águas de Vaso Sanitário (AVS) o efluente com maior carga de matéria orgânica, nutrientes e patógenos, proveniente dos vasos sanitários contendo fezes, urinas e papel higiênico, e Águas Cinzas (AC) advinda dos outros usos diversos no domicílio como pias, chuveiros, ralos e lavatórios, com maiores concentrações de sabão, detergentes e componentes químicos (JABRI et al., 2020; FERNANDES et al., 2019; MELO, 2018; NUÑEZ et al., 2014; PALMQUIST; HANÆUS, 2005; PILZ; SATTLER, 2004; OTTERPOHL, 2001).

A AC pode corresponder de 50 a $82 \%$ do uso total na residência, contudo a AVS, mesmo gerada em menor volume, possui elevado potencial de contaminação e risco à saúde pela presença de nutrientes e patógenos (GALBIATI, 2009; DEL PORTO; STEINFELD, 2000).

Nota-se que tanto as AC quanto as AVS necessitam de tratamento adequado antes da destinação final do efluente e devem-se considerar as suas características físico-químicas específicas e os diferentes potenciais de contaminação.

Como a situação referente às águas de vaso sanitário do lote selecionado era bastante precária, os moradores e o grupo optaram por focar no tratamento das AVS e sua correta destinação final.

Os moradores constataram que a declividade do terreno, cerca de $10 \%$, poderia inviabilizar e encarecer sistemas que necessitem de mais áreas para tratamento e, consequentemente, maior movimentação de terra, como é o caso do tanque de evapotranspiração.

Também foi levantada a hipótese da construção de um banheiro seco. Entretanto, por motivos de foro íntimo e aspectos culturais e sociais, os moradores retrataram que não seria efetivo, ou seja, o mesmo não seria usado.

Os moradores relataram experiências positivas de outros assentados que utilizaram tanques sépticos para tratamento do esgoto doméstico, guiando assim o estudo para sistemas de tratamento semelhantes, visando melhor aceitação por parte de quem utilizará a tecnologia no cotidiano. 
Deste modo, iniciou-se uma busca na literatura para embasar a construção de um sistema de tratamento descentralizado, partindo da caracterização das AVS (Tabela 1).

Tabela 1 - Caracterização das águas de vaso sanitário.

\begin{tabular}{cccc}
\hline Parâmetros & Valor $^{\mathbf{1}}$ & Valor $^{\mathbf{2}}$ & Unidade \\
\hline $\mathrm{pH}$ & 7,5 & 7,84 & - \\
Sólidos Suspensos Totais (SST) & 2296 & 2365 & $\mathrm{mg} . \mathrm{L}^{-1}$ \\
Demanda Química de Oxigênio (DQO) & 6857 & 6619 & $\mathrm{mgO}_{2} . \mathrm{L}^{-1}$ \\
Demanda Bioquímica de Oxigênio (DBO) & 1757 & 1893 & $\mathrm{mgO} . \mathrm{L}^{-1}$ \\
Nitrogênio Total Kjeldahl (NTK) & 454 & 365 & $\mathrm{mgN} . \mathrm{L}^{-1}$ \\
Fósforo Total (FT) & 20,4 & - & $\mathrm{mgP.L}{ }^{-1}$ \\
Coliformes Totais & - & $1,5.10^{9}$ & $\mathrm{NM}-$ \\
& & & $\mathrm{P} .100 \mathrm{~mL}^{-1}$
\end{tabular}

Fonte: Gonçalves et al. (2006) ${ }^{1}$ e Rebouças, Bianchi e Gonçalves (2007) ${ }^{2}$.

Ambos os trabalhos caracterizam as AVS compondo amostras com 6 litros de água, sendo $250 \mathrm{ml}$ de urina, fezes e papel higiênico. Essa proporção corresponde à descarga estimada da geração relativa de uma pessoa adulta. Foram observadas elevadas concentrações de DBO, DQO, NTK e coliformes totais, poluentes que facilmente podem contaminar corpos hídricos se descartados sem tratamento.

Pelas características do esgoto produzido no lote, foram observadas grandes eficiências de remoção de matéria orgânica e outros poluentes do esgoto sanitário a partir da utilização de bactérias que realizam processos biológicos em unidades de tratamento anaeróbios (METCALF; EDDY, 2016; FORESTI; ZAIAT; VALLERO, 2006).

Nesse caso, o sistema mais comum para tratamento descentralizado é o tanque séptico, devido a sua simplicidade e eficiência de remoção de materiais sedimentáveis e flutuantes e pela digestão de matéria orgânica sem a presença de oxigênio (CHERNICHARO, 2007).

A NBR 13969 (ABNT, 1997) apresenta possibilidades de promover tratamento complementar pós tanque séptico, incluindo valas de filtração, filtro de areia, lagoas com plantas aquáticas, lodo ativado por batelada e filtro anaeróbio de leito fixo com escoamento ascendente.

Destaca-se o Filtro Anaeróbio como alternativa viável pois o mesmo promove o tratamento com menores custos de aplicação e operação, com menores demandas 
energéticas e de área (OLIVEIRA JÚNIOR, 2013).

Os tanques sépticos seguidos de filtros anaeróbios apresentam grande potencial de promoção do tratamento de esgoto descentralizado em regiões periféricas/rurais, (MANARIOTIS; GRIGOROPOULOS, 2006; VIANNA; MESQUITA; ROSA, 2018).

Gomes (2015) utilizou tanque séptico seguido de filtro anaeróbio e filtro de areia como tratamento descentralizado em Campinas/SP. Nesse estudo, utilizou-se cascas de coco no filtro anaeróbio como meio suporte e, nas condições experimentais, observou-se eficiência de remoção de poluentes suficientes para disposição final, segundo a legislação.

Com isso, optou-se pelo tanque séptico e filtro anaeróbio seguido de uma zona de raízes (Figura 2) para aplicação no lote selecionado e, permeando o conceito de tecnologia social, buscou-se reduzir os custos do projeto para torná-lo o mais acessível possível. Assim, como meio suporte para o filtro anaeróbio, foi utilizado entulho moído, fornecido por uma empresa da cidade. Esse meio, além de fornecido gratuitamente, engloba a perspectiva ambiental de reaproveitamento de resíduos sólidos de construção civil.

Figura 2 - Representação da tecnologia de tanque séptico, filtro anaeróbico e zona de raízes.

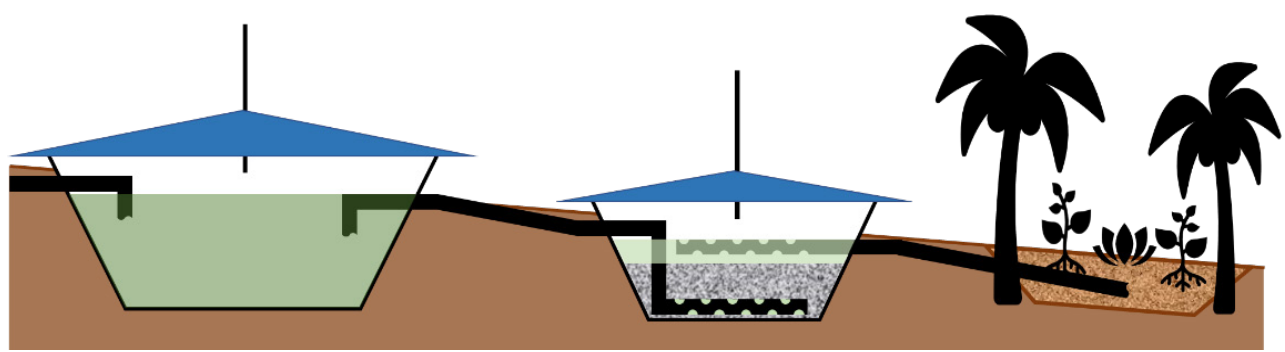

Fonte: Autoria Própria.

Com a confirmação da tecnologia a ser adotada por parte dos moradores, bem como do local de implementação do sistema, deu-se início a fase de dimensionamento do sistema.

O dimensionamento da tecnologia seguiu as normas NBR 7229 (1993) e NBR 13969 (1997) para o tanque séptico e para o filtro anaeróbio, respectivamente. Apesar de possuir 4 residentes no lote, a tecnologia foi projetada para 6 pessoas, estimando o aumento no número de moradores ao longo do tempo. O sistema implementado possui vida útil de 20 a 30 anos incluindo monitoramento e limpezas anuais.

A limpeza anual envolve a remoção de lodo no primeiro tanque séptico através de 
caminhão limpa-fossa e o manejo da zona de raízes na disposição final do efluente, adicionando mais plantas quando necessário ou removendo quando o crescimento é exacerbado.

Os materiais utilizados foram tubos de PVC de $100 \mathrm{~mm}$, conexões, colas, ferramentas, entulho moído, caixas d'água de 1000 e 2000 litros (filtro anaeróbio e tanque séptico, respectivamente) e mudas de plantas (bananeira e taioba). O custo total de implementação da tecnologia foi de R \$ 1.700. Entretanto, como as duas caixas d’água foram doadas pela Coordenação do Curso (CoC) da Engenharia Ambiental da EESC/USP, o grupo de trabalho arcou apenas com o restante das despesas ( $\mathrm{R} \$ 500)$ para os demais materiais.

\section{RESULTADOS E DISCUSSÕES}

\section{IMPLEMENTAÇÃO DO TANQUE SÉPTICO E DO FILTRO ANAERÓBIO}

A implementação do tanque séptico e do filtro anaeróbio foi realizada em formato de oficina com o intuito de agregar mão de obra e de promover a educação ambiental para todos os participantes: moradores, membros discentes e docentes do grupo extensionista GEISA e público interessado.

A oficina foi dividida em dois momentos: Formação e Aplicação.

A formação ocorreu no período da manhã e teve início com uma roda de conversa com os presentes, sendo apresentados os moradores do assentamento, os universitários e demais interessados. Na sequência foi discutido o espaço de atuação (porque atuar em assentamentos rurais e a importância do vínculo extensionista universitário); educação ambiental; a história e realidades presentes no assentamento Nova São Carlos; a importância da promoção do saneamento rural; e a forma de construção e detalhamento da tecnologia social aplicada possibilitando que outras pessoas tenham acesso ao "como fazer". Todos esses tópicos estavam presentes em uma cartilha distribuída no início da formação (Figura 3).

O segundo momento foi dedicado à construção da tecnologia em si, onde os presentes se revezaram nas funções previamente instruídas pelos (as) membros (as) do grupo para a implementação do sistema. Foram escavados dois buracos para a instalação das caixas d'água, assim como cortados e colados os tubos e conexões da rede sanitária do banheiro à tecnologia. Também foram realizados o manejo das mudas de bananeira e taioba na zona de raízes ao final do sistema (Figuras 4 e 5). 
Figura 3 - Dia da aplicação da tecnologia (a) membra no GEISA iniciando a formação e (b) moradora apresentando o assentamento e a residência.

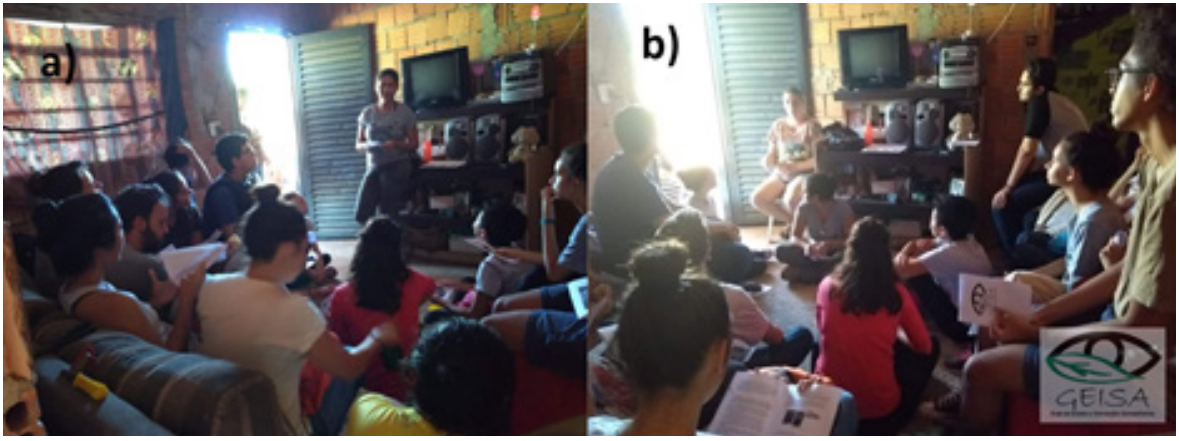

Fonte: Acervo Próprio.

Figura 4 - Construção da tecnologia.

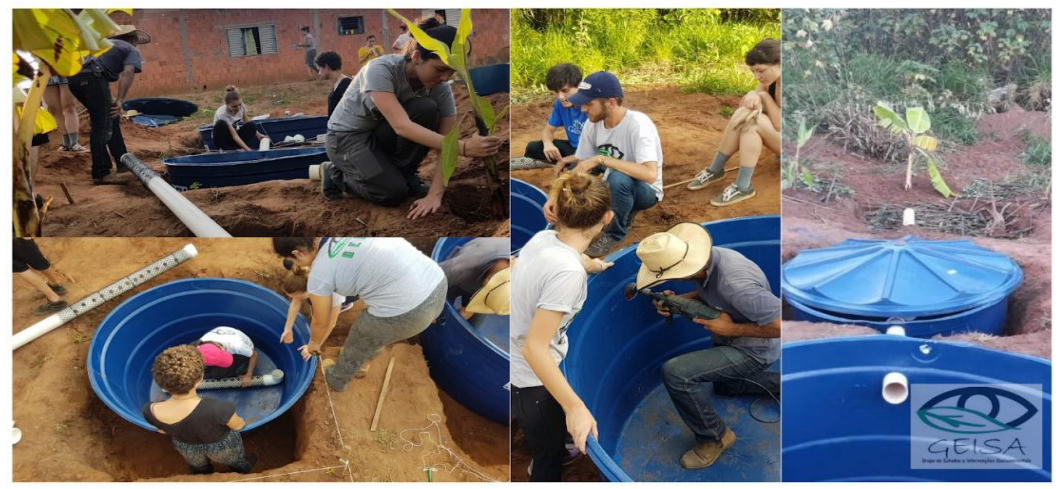

Fonte: Acervo Próprio.

Figura 5 - Participantes da oficina realizada no dia 9 de março de 2019.

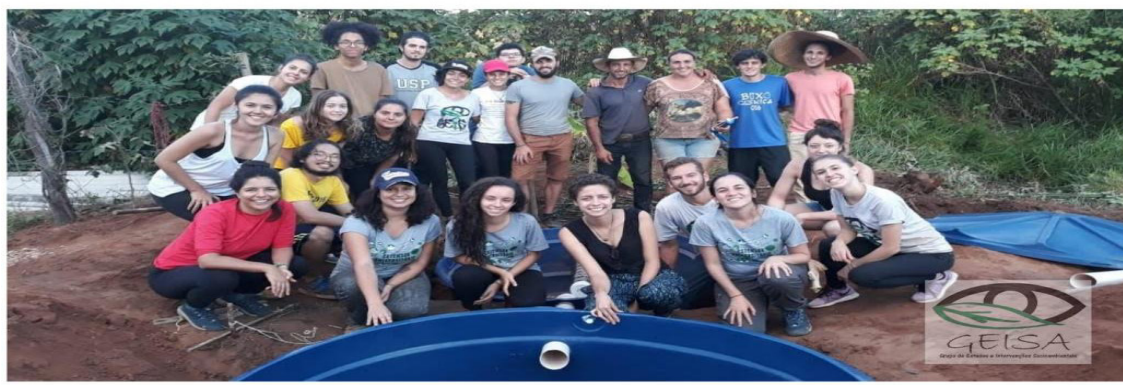

Fonte: Acervo Próprio.. 


\section{Monitoramento}

Após a oficina, foi mantido o contato com os moradores e realizadas visitas ao lote para monitorar o andamento do sistema. Nesta etapa, foram encontradas dificuldades no que tange ao monitoramento qualitativo de eficiência de tratamento.

Por mais que o sistema esteja em operação, ainda não foi possível realizar as análises físico-químicas do afluente e do efluente da tecnologia para constatar e validar a eficiência de tratamento quanto a remoção de poluentes, incluindo matéria orgânica, nitrogênio, fósforo e microrganismos. Tal monitoramento é imprescindível para consolidar o sistema de tratamento como eficaz.

Por parte dos moradores, não foram reportadas necessidades de chamar um caminhão limpa-fossa para manutenção do tanque séptico e não foi necessário adicionar novas plantas à zona de raízes, o que indica que a quantidade de efluente gerado está sendo consumida pelas plantas alocadas.

Com intuito de estimular a apropriação da tecnologia, os moradores que utilizam o sistema possuem total controle do mesmo e, caso seja de interesse dos mesmos, eles podem alterar, modificar e/ou aperfeiçoar o sistema. Ademais, o GEISA se colocou disponível para contato em caso de eventualidades que demandem a atuação do grupo.

\section{CONSIDERAÇões FINAIS}

Com a análise do diagnóstico e o debate entre os membros do grupo, foi possível selecionar um lote do assentamento que, em virtude de aspectos ambientais, econômicos e sociais, necessitava de soluções para saneamento, especificamente para o tratamento do esgoto sanitário. Já a prática dialógica com os moradores e o levantamento bibliográfico permitiram a adoção da melhor alternativa para aquele contexto, sendo projetado e implantado um tanque séptico seguido de filtro anaeróbio e zona de raízes para tratar as AVS da residência.

A aplicação em formato de oficina serviu como ferramenta de troca de saberes, vivências e educação ambiental, contribuindo para formação pessoal, acadêmica e coletiva dos envolvidos: membros do grupo extensionista, assentados e participantes convidados. Tal fato propiciou um debate integrado sobre as temáticas de saneamento rural, tecnologia social, assentamentos da reforma agrária e inclusão social. Configurando-se assim como um momento rico e inovador de ensino e aprendizagem, de impossível reprodução através de práticas pedagógicas expositivas em sala de aula e ou laboratórios.

Essencialmente, a implementação da tecnologia evidenciou a importância de 
um olhar integrado entre Ensino, Pesquisa e Extensão ${ }^{4}$ para construção do conhecimento de todos os envolvidos. Assim, a extensão possibilitou a troca de saberes com os assentados a partir de um projeto aplicado à solução de problemas; a pesquisa propiciou maneiras para encontrar a melhor solução para os problemas enfrentados pelos moradores da residência com base em condicionantes técnicas, sociais e culturais; e o ensino esteve presente em todos os momentos, desde a concepção até a aplicação do sistema de tratamento, promovendo o aprendizado a todos - alunos e alunas, moradores e demais participantes - sobre saneamento rural e tecnologia social. ${ }^{1}$

Também foi fortalecida a relação entre a Universidade e a zona rural de São Carlos através do incentivo ao desenvolvimento contínuo de projetos extensionistas e pesquisas em comunidades vulneráveis com intuito de gerar conteúdo crítico e promover o debate sobre a potencialidade do uso de tecnologias alternativas e descentralizadas de saneamento no campo das políticas públicas para o meio rural.

Por fim, seguindo os critérios de tecnologia social enunciados por Rodrigues e Barbieri (2008), foi compreendido que o sistema implementado em questão pode ser considerado uma tecnologia social a ser aplicada no meio rural por: (1) atender demandas concretas no contexto do estudo de caso; (2) tomar decisões em conjunto com os moradores, os quais possuem o domínio da tecnologia; (3) participação dos agentes envolvidos em todas as etapas (concepção, implementação e operação); (4) organização para aplicação prática do conhecimento teórico; (5) produção de novos conhecimentos gerados pelo contato entre ambiente universitário e assentamento de reforma agrária; (6) promoção da sustentabilidade; (7) ampliação da escala de fomento a pesquisas e experiências de extensão universitária no meio rural pela produção geração de conteúdo crítico e promoção do debate no campo das políticas públicas.

Entretanto, vale mencionar as dificuldades encontradas para o monitoramento da eficiência do sistema envolvendo as dificuldades logísticas de deslocamento até o assentamento, o que prejudica a coleta de amostras, assim como questões burocráticas de acesso aos laboratórios da universidade e a falta de recursos financeiros para aquisição de reagentes.

\section{Agradecimentos}

Agradecemos aos demais integrantes do GEISA pelo trabalho e por fortalecer a extensão universitária no curso de Engenharia Ambiental da EESC/USP; aos participantes da oficina para aplicação da tecnologia; à Coordenação do Curso da

\footnotetext{
${ }^{1}$ Ensino, Pesquisa e Extensão dão sustento às universidades brasileiras, amparados pela lei (Art. 207 da CF de 1988) e, segundo Moite e Andrade (2009), estes 3 pilares nos quais a universidade se apoia, auxiliam a instituição a exercer sua função ética, politica e social para com a sociedade.
} 
Engenharia Ambiental da EESC/USP pela doação das caixas d'água e, principalmente, aos assentados, pelo aprendizado e trabalho em conjunto nessa experiência.

\section{REFERÊNCIAS}

AB'SABER, Aziz Nacib. Geografia e planejamento. Revista de História, v. 39, n. 80, p. 257-271, 1969.

ARAVÉCHIA JÚNIOR, J.C. Indicadores de Salubridade Ambiental (ISA) para a região Centro-Oeste: um estudo de caso no Estado de Goiás. Dissertação (Mestrado) - Universidade Católica de Brasília, Brasília, 2010.

ABNT - Associação Brasileira de Normas Técnicas. NBR 13969: Tanques sépticos - Unidades de tratamento complementar e disposição final dos efluentes líquidos - Projeto, construção e operação; 1997.

ABNT - Associação Brasileira de Normas Técnicas. NBR 7229: Projeto, construção e operação de sistemas de tanques sépticos, 1993.

BATISTA, M. E. M.; SILVA, T. C. O modelo ISA/ JP - indicador de performance para diagnóstico do saneamento ambiental urbano. Engenharia Sanitária e Ambiental, v.11, n.1, p. 55-64, mar. 2006. DOI: http:// dx.doi.org/10.1590/S141341522006000100008

BRASIL. Constituição (1988). Constituição da República Federativa do Brasil. Brasília, DF: Centro Gráfico, 1988.

BRASIL. Lei $n^{\circ} 11.445$, de 5 de janeiro de 2007. Estabelece diretrizes nacionais para o saneamento básico.

BRASIL. Ministério do Desenvolvimento Regional Secretaria Nacional de Saneamento. Plano Nacional de Saneamento Básico - PLANSAB de Março de 2019. Disponível em: https://www.cidades.gov.br/images/stories/ArquivosSNSA/ Arquivos_PDF/plansab/Versaoatualizada07mar2019_consultapublica.pdf. Acesso em 19 de Abril 2020.

BUGELLI, Camila Barcellos; FELÍCIO, Júlia Dedini. Saneamento rural: a experiência 
da implementação de uma tecnologia de saneamento no Assentamento Nova São Carlos (São Carlos-SP). Revista Tecnologia e Sociedade, Curitiba, v. 15, n. 35, p. 78-91, jan./abr. 2019. Disponível em: <https://periodicos.utfpr.edu.br/rts/article/ view/7698>. Acesso em: 19 de Abril 2020.

CHERNICHARO, Carlos Augusto de Lemos. Reatores anaeróbios. 2. ed. Belo Horizonte: Departamento de Engenharia Sanitária e Ambiental. Universidade Federal de Minas Gerais, 2007. 380 p. (Princípios do tratamento biológico de águas residuárias, v.5).

DAGNINO, Renato. Tecnologia Social: contribuições conceituais e metodológicas [online]. Campina Grande: EDUEPB, 2014, 318 p. ISBN 978-85-7879-327-2. Available from SciELO Books <http://books.scielo.org >

DAGNINO, Renato. Em direção a uma Estratégia para a redução da pobreza: a Economia Solidária e a Adequação Sócio-técnica. Organização dos Estados Ibero-americanos para a Educação, a Ciência e a Cultura, 2002.

DE MARQUE, Mário Berni; FANTIN, Marcel. Implementação de tecnologia de saneamento rural no assentamento Nova São Carlos, São Carlos - SP. In Resumos. São Carlos: IAU/USP. Recuperado de https://www.iau.usp.br/pesquisa/images/ Informativo/Caderno_26_SIICUSP_IAU.pdf. 2018.

DEL PORTO, David; STEINFELD, Carol. The composting toilet system book : a practical guide to choosing, planning and maintaining composting toilet systems. Massachussetts. The Center for Ecological Pollution Prevention, 2000. 235 p.

FERNANDES, José Wanderson de Andrade; NETO, Renato Américo Araujo; FARIAS, Joelmir José Albuquerque; AMORIM, Ranieri Carlos Ferreira . QUANTITATIVO DE ÁGUAS CINZAS E NEGRAS EM BANHEIROS DE UM CENTRO UNIVERSITÁRIO EM MACEIÓ-ALAGOAS. Revista Engenharia e Tecnologia Aplicada-UNG-Ser, 2(1), 5-8. 2019

FORESTI, Eugênio. Tratamento de esgoto. Org. CALIJURI, Maria do Carmo; CUNHA, Davi Gasparini Fernandes. Engenharia ambiental: conceitos, tecnologia e gestão. 2013.

FORESTI, Eugênio; ZAIAT, Marcelo; VALLERO, Marcus Vinicius Guerini. 
Anaerobic Processes as the Core Technology for Sustainable Domestic Wastewater Treatment: Consolidated Applications, New Trends, Perspectives, and Challenges. Reviews in Environmental Science and Bio/Technology, 5(1), 3-19. 2006. doi:10.1007/s11157-005-4630-9

GALBIATI, Adriana Farina. Tratamento domiciliar de águas negras através de tanque de evapotranspiração. 2009. Campos Grande. Dissertação (Mestrado) Universidade Federal de Mato Grosso do Sul, Brasil.

GOMES, Bianca Graziella Lento Araujo. Tratamento de esgoto de pequena comunidade utilizando tanque séptico, filtro anaeróbio e filtro de areia. 2015. 1 recurso online ( 138 p.). Dissertação (mestrado) - Universidade Estadual de Campinas, Faculdade de Engenharia Civil, Arquitetura e Urbanismo, Campinas, SP. Disponível em: <http://www.repositorio.unicamp.br/handle/REPOSIP/258423>. Acesso em: 18 de Abril 2020

GONÇALVES, Ricardo Franci et al. Desinfecção de Efluentes Sanitários. Vitória: Associação Brasileira de Engenharia Sanitária e Ambiental (Abes), 2003. p 435

GONDIM, G.M.M. Espaço e saúde: uma (inter)ação provável nos processos de adoecimento e morte em populações. In: MIRANDA, A.C.; BARCELLOS, C.; MOREIRA, J.C.; MONKEN, M. Território, ambiente e saúde. Rio de Janeiro: Editora Fiocruz, 2008.

FERRANTE, Vera Lucia Silveira Botta; WHITAKER, Dulce Consuelo Andreatta. Revista do Núcleo de Pesquisa e Documentação Rural (Nupedor) - Retratos de Assentamentos. Vol.16. No02. 2013.

HELLER, Léo. Relação entre saúde e saneamento na perspectiva do desenvolvimento. Ciência \& Saúde Coletiva, v. 3, n. 2, p. 73-84, 1998.

GERMANI, Alessandra Regina Müller; VILLWOCK, Ana Paula Schervinski; CHIES, Jacir João. Construindo uma rede solidária e de cooperação na produção das ações de saúde no contexto da luta pela terra. Retratos de Assentamentos, v. 23, n. 2, p. 156-173, 2020. 
GONÇALVES, Ricardo Franci et al. Caracterização e Tratamento de diferentes tipos de águas residuárias de origem residencial após segregação. AIDIS-Asociación Interamericana de Ingeniería Sanitaria y Ambiental. SecciónUruguay. Rescatando Antiguos Principios para os Nuevos Desafíos Del Milenio. Monte video, p. 1-10, 2006.

HOLGADO-SILVA, Heloiza Cristina et al. A qualidade do saneamento ambiental no Assentamento Rural Amparo no município de Dourado-MS. Sociedade \& Natureza, [s.l.], v. 26, n. 3, p.535-545, dez. 2014. FapUNIFESP (SciELO). Disponível em: <http://dx.doi.org/10.1590/1982-451320140311.>. Acesso em: 19 de Abril 2020

INSTITUTO BRASILEIRO DE GEOGRAFIA E ESTATÍSTICA (IBGE). Pesquisa Nacional por Amostra de Domicílio - Síntese dos Indicadores. Rio de Janeiro: IBGE. 2015.

INSTITUTO DE TECNOLOGIA SOCIAL (ITS). Reflexões sobre a construção do conceito de tecnologia social. In: DE PAULO, A. et al. Tecnologia Social: uma estratégia para o desenvolvimento. Rio de Janeiro: Fundação Banco do Brasil, 2004.

JABRI, Khaoula Masmoudi; NOLDE, Erwin; CIROTH, Andreas.; BOUSSELMI, Latifa. Life cycle assessment of a decentralized greywater treatment alternative for non-potable reuse application. International journal of environmental science and technology, 17, 433-444. 2020. doi: 10.1007/s13762-019-02511-3

JORDÃO, Eduardo Pacheco; PESSÔA, Constantino Arruda. Tratamento de esgotos domésticos. Cetesb, 1975.

LEONETI, Alexandre Bevilacqua; PRADO, Eliana Leão do; OLIVEIRA, Sonia Valle Walter Borges de. Saneamento básico no Brasil: considerações sobre investimentos e sustentabilidade para o século XXI. Revista de Administração Pública, v. 45, n. 2, p. 331-348, 2011.

LIBRALATO, Giovanni; GHIRARDINI, Annamaria Volpi; AVEZZÜ, Francesco. To centralize or to decentralize: An overview of the most recent trends in wastewater treatment management. Journal of Environmental Management v. 94. p. 61- 68. 2012.

LOTFI, Pedro Carlos Sztajn. Avaliação preliminar da eficiência de fossas 
biodigestoras no tratamento de esgoto unidomiciliar - Assentamento Nova São Carlos e Santa Helena, São Carlos (SP). 2016. 79 f. TCC (Graduação) - Curso de Engenharia Ambiental, Universidade de São Paulo, São Carlos, 2016.

MANARIOTIS, Ioannis; GRIGOROPOULOS, Sotirios. Municipal-Wastewater Treatment Using Upflow-Anaerobic Filters. Water Environment Research, 78: 233-242. 2006. doi:10.2175/106143005X90029

MELO, Mikhael Rangel de Souza. Estratégias de aplicação de efluente de água cinza no cultivo do girassol ornamental. 2018. 73 f. Dissertação (Mestrado) Curso de Mestrado em Manejo de Solo e Água, Universidade Federal Rural do Semi-Árido, Mossoró, 2018.

METCALF, Leonard; EDDY, Harrison. Tratamento de efluentes e recuperação de recursos. Tradução: Ivanildo Hespanhol, José Carlos Mierzwa. $5^{\text {a }}$ ed. Porto Alegre: AMGH. 2016.

MINISTÉRIO DO DESENVOLVIMENTO AGRÁRIO - MDA; INSTITUTO NACIONAL DE COLONIZAÇÃO E REFORMA AGRÁRIA - INCRA. SUPERINTENDÊNCIA REGIONAL DE SÃO PAULO. Relatório de Gestão do Exercício de 2009. Disponível em: http://www.incra.gov.br/sites/default/files/uploads/servicos/ publicacoes/relatorios/relatoriosde-gestaao/2014/sr08-sp.pdf Acesso em 20 de Abril 2020.

MOISÉS, Marcia; KLIGERMAN, Débora Cynamon; COHEN, Simone Cynamon; MONTEIRO, Sandra Conceição Ferreira. A política federal de saneamento básico e as iniciativas de participação, mobilização, controle social, educação em saúde e ambiental nos programas governamentais de saneamento. Ciência \& saúde coletiva, v. 15, p. 2581-2591, 2010.

MOITA, Filomena Maria Gonçalves da Silva Cordeiro; ANDRADE, Fernando Cézar Bezerra de. Ensino-pesquisa-extensão: um exercício de indissociabilidade na pósgraduação. Rev. Bras. Educ., Rio de Janeiro , v. 14, n. 41, p. 269-280, Aug. 2009.

Disponível em: http://www.scielo.br/scielo.php?script=sci_arttext\&pid=S141324782009000200006\&lng=en\&nrm=iso. Acesso em 07 de Maio de 2020. DOI: $10.1590 /$ S1413-24782009000200006.

MURTHA, Ney Albert; CASTRO, José Esteban; HELLER, Léo. Uma perspectiva 
histórica das primeiras políticas públicas de saneamento e de recursos hídricos no brasil. Ambiente \& Sociedade, 18(3), 193-210. 2015. https://doi.org/10.1590/18094422ASOC1047V1832015

MURTHA, Ney Albert; CASTRO, José Esteban; HELLER, Léo. Uma perspectiva histórica das primeiras políticas públicas de saneamento e de recursos hídricos no brasil. Ambiente \& Sociedade, 18(3), 193-210. 2015. https://doi.org/10.1590/18094422ASOC1047V1832015

NUÑEZ, Lidia; MOLINARI, Claudia; PAZ, Marta; TORNELLO, Carina; MANTOVANO, Julián; MORETTON, Juan. Análisis de riesgo sanitario en aguas grises de la provincia de Buenos Aires, Argentina. Revista internacional de contaminación ambiental, 30(4), 341-350. 2014.

OLIVEIRA JÚNIOR, José Lima. Tratamento descentralizado de águas residuárias domésticas: uma estratégia de inclusão social. LIRA, WS., and C NDIDO, GA., orgs. Gestão sustentável dos recursos naturais: uma abordagem participativa. Campina Grande: EDUEPB, p. 213-232, 2013.

OTTERPOHL, Ralf. Black, brown, yellow, grey - the new colors of sanitation. Water 21. p37-41, out. 2001.

PALMQUIST, Helena; HANÆUS, Jörgen. Hazardous substances in separately collected grey-and blackwater from ordinary Swedish households. Science of the Total Environment, v. 348, n. 1-3, p. 151-163, 2005.

PERRIN, Anaïs Guéguen; FERREIRA, Thiago Lopes. Casa Suindara: formação, experimentação e construção no habitat rural. Paranoá: Cadernos De Arquitetura E Urbanismo, (17). 2017. https://doi.org/10.18830/issn.1679-0944.n17.2016.09

PILZ, Silvio Edmundo; SATTLER, Miguel Aloysio. Banheiros compostáveis: uma solução mais sustentável evitando a geração de águas negras. In: Congresso brasileiro de ciência e tecnologia em resíduos e desenvolvimento sustentável. Anais... Costão do Santinho-Florianópolis-Santa Catarina. 2004.

PITASSI, Sandro Lucio Barbosa. Direitos humanos, saúde e saneamento: aspectos conceituais e regulatórios e os desafios para a adoção de políticas públicas. Dissertação (mestrado) - Fundação Oswaldo Cruz, Escola Nacional de Saúde 
Pública Sergio Arouca, Rio de Janeiro, 2019.

PRÜSS, A.; KAY, D.; FEWTRELL, L.; BARTRAM, J. Estimating the burden of disease from water, sanitation, and hygiene at a global level. Environmental Health Perspectives, v. 110, n. 5, p. 537-542, 2002.

REBOUÇAS, Thais. Cardinali; BIANCHI, Gabriela; GONÇALVES, Ricardo Franci. Caracterização de águas residuárias de origem residencial. In: Conferência Internacional em Saneamento Sustentável: Segurança alimentar e hídrica para a América Latina, Fortaleza. 2007.

RODRIGUES, Ivete; BARBIERI, José Carlos. A emergência da tecnologia social: revisitando o movimento da tecnologia apropriada como estratégia de desenvolvimento sustentável. Revista de Administração Pública, Rio de Janeiro , v. 42, n. 6, p. 1069-1094, Dec. 2008 . Available from <http://www.scielo.br/scielo. php?script=sci_arttext\&pid=S0034-76122008000600003\&lng=en\&nrm $=\mathrm{iso}>$. Acesso em 20 Abril 2020. https://doi.org/10.1590/S0034-76122008000600003.

SAWAIA, Bader Burihan. Psicologia e desigualdade social: uma reflexão sobre liberdade e tranformação social. Psicol. Soc., Florianópolis, v. 21, n. 3, p. 364-372, Dec. 2009. https://doi.org/10.1590/S0102-71822009000300010.

SILVA, Suzana de Araújo; GAMA, José Aparecido da Silva; CALLADO, Nélia Henriques; SOUZA, Vladimir Caramori Borges de. Saneamento básico e saúde pública na bacia hidrográfica do Riacho Reginaldo em Maceió, Alagoas. Engenharia Sanitaria e Ambiental, v. 22, n. 4, p. 699-709, 2017.

SIMONATO, Danitielle Cineli et al. Saneamento rural e percepção ambiental em um assentamento rural - São Paulo - Brasil. Retratos de Assentamentos, v. 22, n. 2, p. 264-280, 2019.

SOUZA, M. P. Instrumentos de Gestão Ambiental: Fundamentos e Prática. São Carlos. 112 p.Ed. Riani Costa. 2000.

SOUZA, Marcos José; FERNANDES, Elaine; CARVALHO, Lucas Vitor. Determinantes estructurales en la difusión de las patologías del agua en Brasil. Problemas del Desarrollo. Volume 45, Issue 179. 2014. Pages 117-136. ISSN 03017036. https://doi.org/10.1016/S0301-7036(14)70143-9. 
SOUZA-ESQUERDO, Vanilde Ferreira; BERGAMASCO, Sonia Maria Pessoa Pereira. Reforma Agrária e Assentamentos Rurais: perspectivas e desafios. In: V Jornadade Estudos em Assentamentos Rurais. Campinas, SP, 2011. Disponível em: <http://transformatoriomargaridas.org.br/sistema/wp-content/ uploads/2015/02/1406231456wpdm_Texto-REFORMA-AGR\%C3\%81RIA-EASSENTAMENTOS-RURAIS-PERSPECTIVAS-E-DESAFIOS-.pdf> .Acesso em: 23 de Abril 2020

TABARIN, Isadora Andrade; FANTIN, Marcel. Estudos e aplicações de metodologias para o Diagnóstico Socioambiental do Assentamento Nova São Carlos - São Carlos (SP) - Segunda edição: etapa qualitativa. Relatório final do Programa Unificado de Bolsas da USP (PUB), 2018.

TRATABRASIL. Novo Ranking do Saneamento Básico evidencia: melhores cidades em saneamento investem 4 vezes mais que as piores cidades no Brasil. Disponível em: <http://www.tratabrasil.org.br/images/estudos/itb/ranking-2019/ PRESS RELEASE Ranking do Saneamento NOVO.pdf $>$. Acesso: 08 de junho 2021

VARISON, Leticia Rabelo; TAVER, Ligia Cristina; MONTAÑO, Marcelo. Diagnóstico do Assentamento Comunidade Agrária Nova São Carlos e Região (ACASCAR). Relatório final do Programa Unificado de Bolsas da USP (PUB), 2017.

TONETTI, Adriano Luiz; BRASIL, Ana Lúcia; MADRID, Francisco José Peña y Lillo; FIGUEIREDO, Isabel Campos Salles; SCHNEIDER, Jerusa; CRUZ, Luana Mattos de Oliveira; DUARTE, Natália Cangussu; FERNANDES, Patrícia Moreno; COASACA, Raúl Lima; GARCIA, Rodrigo Sanches; MAGALHÃES, Taína Martins. Tratamento de esgotos domésticos em comunidades isoladas: referencial para a escolha de soluções. Biblioteca/Unicamp. Campinas, São Paulo, v. 153, 2018.

VIANNA, Thomás Corrêa; MESQUITA, Tayane Cristiele Rodrigues; ROSA, André Pereira. Panorama do emprego de tanques sépticos e filtros anaeróbios no tratamento descentralizado de efluentes no Sudeste brasileiro. Edição especial saneamento rural, p. 157, 2019.

VON SPERLING, Marcos. Introdução à qualidade das águas e ao tratamento de esgotos. Editora UFMG, 1996. 